\title{
STUDI EKSPERIMEN PENGARUH WICK SUMBU KAPILER PADA MODEL LOOP HEAT PIPE
}

\author{
Dimas Panji Asmara ${ }^{1}$, Mukhsinun Hadi Kusuma ${ }^{2 *}$, Giarno ${ }^{2}$, Darwin Rio Budi Syaka ${ }^{1}$ \\ ${ }^{1}$ Pendidikan Teknik Mesin, Universitas Negeri Jakarta J1 Rawamangun Muka Raya, \\ Jakarta 132020 \\ ${ }^{2}$ Pusat Teknologi dan Keselamatan Reaktor Nuklir, Badan Tenaga Nuklir Nasional (BATAN) \\ Kawasan Puspitek Serpong, Tangerang Selatan 15413 \\ *Email: luluikal@batan.go.id
}

\begin{abstract}
ABSTRAK
STUDI EKSPERIMEN PENGARUH WICK SUMBU KAPILER PADA MODEL LOOP HEAT PIPE. Kecelakaan pada Pembangkait Listrik Tenaga Nuklir Fukushima Daiichi memacu para peneliti untuk menggunakan sistem pendingin pasif dalam rangka meningkatkan keselamatan termal isntalasi nuklir. Salah satu teknologi sistem pendingin pasif adalah Loop Heat Pipe (LHP) karena memiliki kemampuan pembuangan kalor yang baik. Tujuan penelitian ini untuk mengetahui pengaruh performa wick berupa sumbu kapiler dalam rangka meningkatkan unjuk kerja termal dan distribusi suhu pada LHP. Metode eksperimen dilakukan dengan mengoperasikan LHP menggunakan suhu air panas sebagai beban kalor di evaporator pada suhu $35^{\circ} \mathrm{C}, 45^{\circ} \mathrm{C}, 55^{\circ} \mathrm{C}$ dan $65^{\circ} \mathrm{C}$. Pendinginan di bagian condenser menggunakan laju aliran udara $2 \mathrm{~m} / \mathrm{s}$. Hasil eksperimen didapatkan suhu pada bagian adiabatic dengan wick lebih rendah dibandingkan pada bagian adiabatic tanpa wick. kesimpulan dari penelitian ini membuktikan bahwa penggunaan wick pada LHP dapat memberikan jalur dari evaporasi yang terjadi di bagian evaporator.

Kata kunci: wick pipa kapiler, Loop Heat Pipe, sistem pendingin pasif , isntalsi nuklir.
\end{abstract}

\section{ABSTRACT}

\section{EXPERIMENTAL STUDY OF THE EFFECT OF CAPILLARY AXXIS WICK ON LOOP}

HEAT PIPE MODEL. The accident at the Fukushima Daiichi Nuclear Power Plant prompted researchers to use passive cooling systems to improve the thermal safety of nuclear installations. One of the passive cooling system technologies is Loop Heat Pipe (LHP) because it has good heat dissipation capabilities. The purpose of this study was to determine the effect of wick performance in the form of a capillary axis in order to improve thermal performance and temperature distribution on the LHP. The experimental method was carried out by operating the LHP using hot water temperature as the heat load in the evaporator at temperatures of $35^{\circ} \mathrm{C}, 45^{\circ} \mathrm{C}, 55^{\circ} \mathrm{C}$ and $65^{\circ} \mathrm{C}$. Cooling in the condenser uses an air flow rate of $2 \mathrm{~m} / \mathrm{s}$. The experimental results showed that the temperature in the adiabatic section with wick was lower than in the adiabatic section without wick. the conclusion of this study proves that the use of a wick on the LHP can provide a path for evaporation that occurs in the evaporator section.

Keywords: capillary pipe wick, Loop Heat Pipe, passive cooling system, nuclear installation. 


\section{PENDAHULUAN}

Berkurangnya sumber energi listrik menjadikan Pembangkit Listrik Tenaga Nuklir (PLTN) digunakan sebagai salah satu alternatif pembangkit energi listrik, Pemakaian teknologi nuklir mempunyai dampak kekurangan dan kelebihan. Salah satu potensi bahaya penggunaan PLTN adalah terlepasnya zat radioaktif apabila terjadi kecelakaan serta kegagalan dalam pengoperasiannya. Jika potensi dari bahaya tersebut terjadi, maka akan memberikan dampak negatif bagi para masyarakat secara luas dan pekerja yang ada di PLTN [1].

Salah satu contoh kecelakaan yang terjadi yaitu pada PLTN di kawasan Fukushima, Jepang tahun 2011. Kecelakaan ini diawali dengan gempa sebesar kurang lebih 9 SR yang melanda Fukushima Jepang, dimana pada kawasan ini terdapat PLTN yang dioperasikan oleh Tokyo Electrical company. PLTN yang dioperasikan oleh industri ini mempunyai jenis boiling water reactor (BWR) generasi ke-2 yang seluruh sistem pendinginnya tergantung pada sistem aktif. Gempa tersebut menyebabkan reaktor shutdown secara otomatis. Gempa ini mengakibatkan rusaknya sistem transmisi listrik yang diperlukan oleh sistem reaktor secara keseluruhan serta mengakibatkan kawasan PLTN ini mengalami Station Black Out (SBO) [1].

Setelah 1 jam terjadi gempa, kemudian tsunami datang sehingga merendam kawasan Vol.25 No. 2 Nov 2021
PLTN mencapai ketinggian $14 \mathrm{~m}$, serta merendam rumah pompa pendingin dan generator listrik. Akibatnya seluruh kawasan PLTN mengalami SBO yang cukup lama. Hal ini menyebabkan terjadinya peningkatan suhu serta tekanan pada teras reaktor yang menyebabkan terjadinya ledakan 4 unit PLTN dari total 6 unit yang terdapat gas hidrogen dikarenakan sisa hasil peluruhan yang dihasilkan dari reaktor tidak bisa dibuang dengan baik ke lingkungan [1].

Peristiwa tersebut menjadi dasar pengembangan untuk terus meningkatkan sistem keselamatan PLTN yang terdapat di seluruh dunia serta dibutuhkan membuat sistem keselamatan untuk reaktor masa depan. Penggunaan sistem keselamatan pasif mulai diperhatikan untuk menunjang sistem pendingin reaktor ketika sistem keselamatan aktif gagal berfungsi akibat terdapatnya kecelakaan. Salah satu teknologi yang digunakan untuk mendinginkan serta membuang panas secara pasif merupakan pemanfaatan teknologi baru loop heat pipe (LHP) [1]-[3].

Pada eksperimen sebelumnya, Kusuma et al. menggunakan heat pipe lurus tanpa sumbu kapiler sebagai sistem pendingin pasif. Hasil yang didapatkan menunjukkan bahwa peningkatan laju aliran pendingin akan mempercepat proses kondensasi di condenser dan akan memperkecil perbedaan suhu evaporator dan condenser sehingga menghasilkan 
tahanan termal pipa kalor terendah [4]. Pada penelitian lainnya Zhu et al. mengenai pengaruh suhu heat sink, karakteristik operasional serta telah memberikan referensi desain sistem pendingin ketika sistem loop heat pipe digunakan pada pendinginan listrik. Hasilnya menghasilkan suhu heat sink yang optimal sebesar $\left(18^{\circ} \mathrm{C}\right)$ dan untuk suhu pada bagian evaporator terendah sebesar $\left(77^{\circ} \mathrm{C}\right)$, waktu start-up terpendek (1000s), tahanan termal terkecil sebesar $(0,29 \mathrm{~K} / \mathrm{W})$, dan panas pada evaporator tertinggi koefisien transfer $\left.\left(3.1 \times 104 \mathrm{~W} / \mathrm{m}^{2} . \mathrm{K}\right)\right)[5],[6]$.

Putra et al. telah melakukan berbagai penelitian mengenai heat pipe sebagai pendingin pasif. Penelitian-penelitian tersebut dilakukan dengan menggunakan berbagai fluida kerja seperti air demineral dan nanofluid. Hasil yang didapatkan bahwa nanofluid berpotensi dapat digunakan sebagai fluida kerja pada heat pipe [7]-[10]. Menurut Vasiliev et al. heat Pipe sudah banyak diaplikasikan pada bidang industri, teknologi elektronik, pemanfaatan gas buang, pemanas udara, sistem HVAC, dan pemanfaatan panas buang dari boiler, melalu penelitian yang telah dilakukan dapat disimpulkan bahwa heat pipe dapat diaplikasikan pada alat penukar kalor terkini karena memiliki kemampuan pemindahan kalor yang baik [11]-[13]. Pada penelitian Grissa et al. heat pipe dibuat sebagai teknologi yang tepat karena mempunyai solusi yang baik dengan desain termalnya yang hemat biaya dan mempunyai perpindahan panas yang sangat baik dengan mempunyai kapabilitas, efisiensi yang tinggi dan kesederhanaan struktural [14], [15].

Penelitian Wang et al. mengenai termal karakteristik hidrolik dan batas perpindahan panas dari heat pipe kalium telah di selidiki dalam studi eksperimennya, dalam eksperimennya tentang kerja perpindahan panas pada suhu tinggi heat pipe kalium, menghasilkan dua sistem percobaan yaitu kondisi berpendingin udara dan pendingin air, telah dirancang dan diterapkan untuk mengetes heat pipe dengan jumlah muatan yang berbeda, jadi kondisi stable dan batas perpindahan panas kinerja dari perpindahan panas heat pipe [6].

Kinerja termal dari heat pipe datar dengan logam telah diteliti secara eksperimental oleh Somasundaram et al [16]. Dengan mengevaluasi pengaruh masukan panas laju aliran air pendingin dan suhu di sisi condenser dan filling ratio fluida kerja di efisiensi termal Copper Flat Heat Pipe, dengan Wick memiliki porositas 0,77 dan $1,114 \times 10^{10} \mathrm{~mm}^{2}$ dan air sebagai fluida kerja. Mereka menyimpulkan dengan penambahan satu dan dua kolom wick dapat menyebabkan penurunan $2,1 \%$ dan $3,1 \%$ dalam resistansi termal. Menurut Odagiri et al. heat Pipe mempunyai perpindahan panas yang tinggi dan memiliki keunggulan lainnya seperti mampu bekerja tanpa tenaga 
dari listrik, serta bekerja dalam keadaan anti gravitasi, heat pipe banyak digunakan selaku perangkat pendingin lampu LED chip dan elektronik selular [17]. Setyawan et al. dalam bagian dinding Heat Pipe yang diisi sumbu kapiler (wick) yang berupa sintered powder, screen mesh dan groove. Berperan sebagai jalur fluida serta pompa kapiler. Heat pipe disebut sebagai superconductor sebab ia mempunyai kapasitas serta kecepatan perpindahan kalor yang luar biasa dengan hampir tidak ada kehilangan kalor [18]. Menurut Liu et al. heat Pipe bekerja dengan aliran fluida kerja dua fasa dalam melakukan perpindahan panasnya, agar efisiensi pada heat pipe lebih tinggi dalam hal kinerja perpindahan panas, Heat Pipe ini mempunyai kelebihan dan mampu dalam hal perpindahan panas yang kuat kapabilitas dengan sedikit perbedaan suhu, fleksibilitas tinggi telah membuat Heat Pipe banyak digunakan pada perangkat elektronik karena memiliki pembuangan panas yang baik [19]

Penelitian mengenai LHP ini merupakan bagian dari penelitian yang masih dalam tahap pengembangan oleh Badan Tenaga Nuklir Nasional, khususnya di Pusat Teknologi dan Keselamatan Reaktor Nuklir. Tujuan penelitian ini adalah untuk mengetahui pengaruh wick pada LHP apakah dapat beroperasi dengan memberikan jalur dari hasil proses evaporasi. Metode eksperimen dilakukan dengan mengoperasikan LHP menggunakan wick.
LHP dioperasikan dengan memvariasikan suhu air panas sebagai beban kalor di evaporator pada suhu $35^{\circ} \mathrm{C}, 45^{\circ} \mathrm{C}, 55^{\circ} \mathrm{C}$ dan $65^{\circ} \mathrm{C}$. Untuk laju aliran udara sebagai pendinginan yang dialirkan ke fin yang menempel pada bagian condenser digunakan sebesar $2 \mathrm{~m} / \mathrm{s}$. dan filling ratio adalah rasio antara volume fluida kerja dengan volume evaporator pada LHP diberikan sebesar $200 \%$.

\section{METODOLOGI}

\section{Eksperimental Setup}

Penelitian ini menggunakan eksperimental setup dan test section seperti yang ditunjukkan pada Gambar 1, dan Gambar 2.

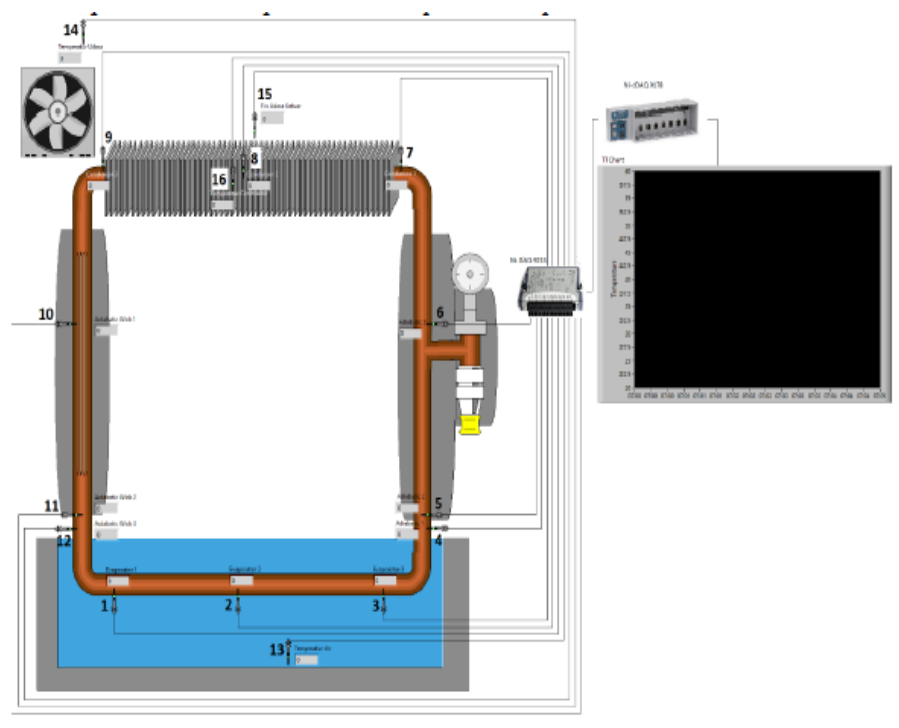

Gambar 1. Eksperimental setup model LHP

Keterangan:
1. Evaporator 1
2. Evaporator 2
3. Evaporator 3
4. Adiabatic 1
5. Adiabatic 2
6. Adiabatic 3
7. Condenser 1
8. Condenser 2 
Eksperimental setup model LHP sebagai sistem pendingin pasif dalam penelitian ini dapat dilihat pada Gambar 1. LHP terbuat dari material pipa tembaga dengan panjang pipa $1200 \mathrm{~mm}$, diameter dalam 8,65 mm, diameter luar 9,55 mm, LHP terdiri atas tiga bagian yang disebut dengan evaporator, adiabatic dan condenser. Bagian evaporator terletak pada bagian bawah dengan panjang sisi tegak masing-masing $50 \mathrm{~mm}$ dan panjang bagian mendatar $300 \mathrm{~mm}$.

Bagian adiabatic yang memiliki panjang masing-masing $200 \mathrm{~mm}$ terletak antara bagian evaporator dan condenser dengan dua jalur yang berbeda, yaitu 1 buah jalur uap dan 1 buah jalur fluida hasil kondensasi. Bagian condenser terletak pada bagian atas dengan panjang sisi tegak masing-masing $50 \mathrm{~mm}$ dan panjang bagian mendatar $300 \mathrm{~mm} \mathrm{[2].}$

Test section model LHP dengan wick dapat dilihat pada Gambar 2.

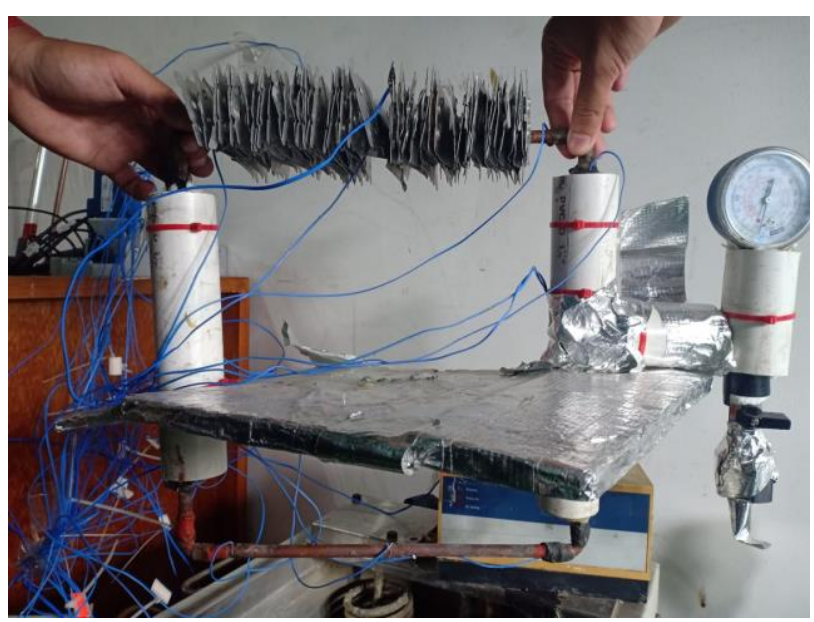

Gambar 2. Test section model LHP dengan wick sumbu kapiler.
Pada gambar 2 ditunjukkan test section model LHP dengan menggunakan wick. Eksperimen dilakukan dengan diberikan suhu pada bagian evaporator sebesar $35^{\circ} \mathrm{C}$, $45^{\circ} \mathrm{C}, \quad 55^{\circ} \mathrm{C}$, dan $65^{\circ} \mathrm{C}$. Model LHP menggunakan filling ratio $200 \%$ dan proses pendinginan diberikan laju aliran $2 \mathrm{~m} / \mathrm{s}$.

Evaporator sebagai bagian yang menyerap kalor direndam di dalam circulating thermostatic bath (CTB) yang berisi air panas. Di dalam pipa evaporator diberikan fluida air demineral. Fluida kerja air demineral dipilih karena memiliki kompatibilitas yang baik dengan material LHP, memiliki merit number yang tinggi, dan stabilitas termal yang baik.

Bagian adiabatic berfungsi sebagai jalur uap dari evaporator menuju condenser dan jalur fluida hasil kondensasi dari condenser menuju evaporator. Pada bagian ini, panas yang berasal dari LHP tidak boleh keluar menuju lingkungan dan sebaliknya. Untuk mengurangi pembuangan kalor ke lingkungan, keseluruhan bagian adiabatic diisolasi dengan material insulasi ceramic blanket, glass wool dan aluminium sheet.

Pada bagian condenser diletakkan fin untuk membantu pembuangan kalor dari condenser ke lingkungan. Fin yang digunakan berbahan aluminium dan memiliki bentuk persegi panjang. Masingmasing fin memiliki panjang $116.3 \mathrm{~mm}$, lebar $45.1 \mathrm{~mm}$, dan tebal $0.4 \mathrm{~mm}$. Fin 
tersebut diletakkan dengan jarak antar fin sebesar $5 \mathrm{~mm}$.

Laju aliran udara yang divariasikan kecepatannya digunakan sebagai media pendingin untuk membuang panas di fin ke lingkungan. Pada eksperimen ini divariasikan beban kalor yang diterima oleh evaporator dan kecepatan udara pendingin yang dialirkan ke permukaan fin. Matriks eksperimen LHP menggunakan wick dapat dilihat pada Tabel 1 .

Tabel 1. Matriks eksperimen model LHP

\begin{tabular}{lllll}
\hline $\begin{array}{l}\text { Fluida } \\
\text { kerja }\end{array}$ & $\begin{array}{l}\text { Filling } \\
\text { ratio } \\
(\%)\end{array}$ & $\begin{array}{l}\text { Laju udara } \\
\text { pendingin } \\
(\mathrm{m} / \mathrm{s})\end{array}$ & $\begin{array}{l}\text { Beban } \\
\text { kalor } \\
\left({ }^{\circ} \mathrm{C}\right)\end{array}$ & $\begin{array}{l}\text { Tekanan } \\
\text { vakum } \\
(\mathrm{cmHg})\end{array}$ \\
\hline \multirow{3}{*}{$\begin{array}{l}\text { Air } \\
\text { demineral }\end{array}$} & 200 & 2 & 35 & -74 \\
& 200 & 2 & 45 & -74 \\
& 200 & 2 & 55 & -74 \\
\hline
\end{tabular}

\section{HASIL DAN PEMBAHASAN}

\section{Distribusi suhu transient LHP}

Hasil eksperimen LHP menggunakan wick pada filling ratio $200 \%$ dengan beban kalor yang divariasikan dari suhu $35^{\circ} \mathrm{C}, 45^{\circ} \mathrm{C}$, $55^{\circ} \mathrm{C}, 65^{\circ} \mathrm{C}$ dan laju aliran udara $2 \mathrm{~m} / \mathrm{s}$ ditunjukkan pada Gambar 3.

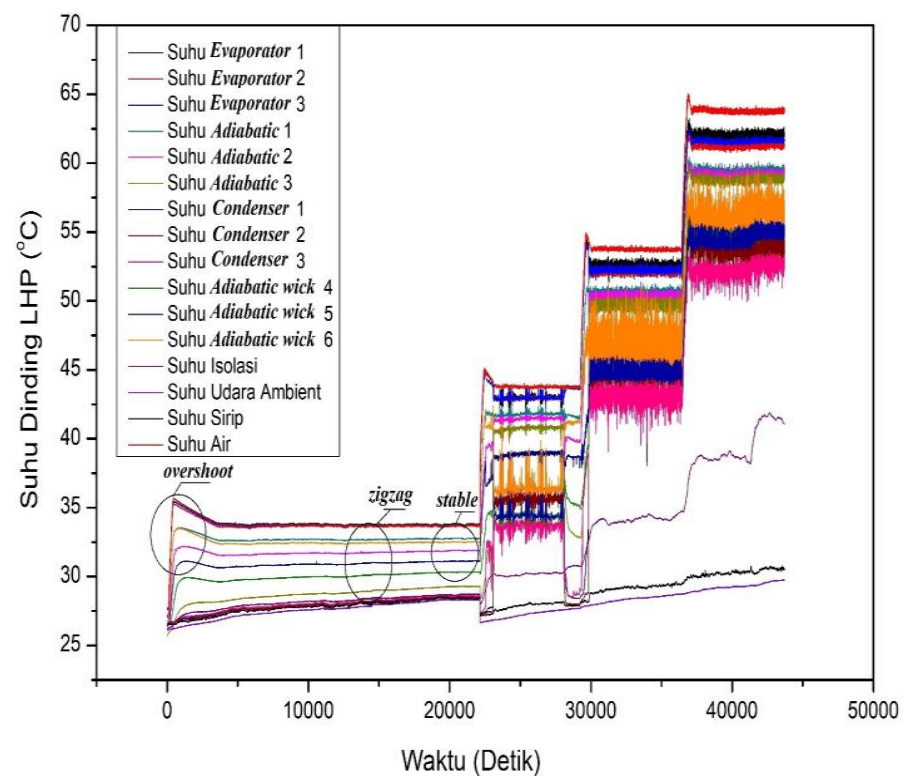

Gambar 3. Distribusi suhu transient LHP menggunakan filling ratio $200 \%$ dan laju aliran udara $2 \mathrm{~m} / \mathrm{s}$

Dari Gambar 3 ditunjukkan suhu transient dengan waktu eksperimen pada suhu $35^{\circ} \mathrm{C}$ selama \pm 6 jam baru didapatkan fenomena steady. Untuk suhu $45^{\circ} \mathrm{C}, 55^{\circ} \mathrm{C}$, dan $65^{\circ} \mathrm{C}$, eksperimen dilakukan selama 1,5 jam untuk mendapatkan fenomena steady tersebut. Fenomena ini logis karena pada suhu $35^{\circ} \mathrm{C}$ dibutuhkan waktu yang cukup lama dikarenakan suhu yang dipanaskan oleh CTB di evaporator cukup rendah sehingga memperlambat proses perpindahan kalor pada model LHP. Pada suhu $45^{\circ} \mathrm{C}, 55^{\circ} \mathrm{C}$, dan $65^{\circ} \mathrm{C}$ memilliki kesamaan waktu untuk mencapai fenomena steady karena semakin besar beban kalor yang diberikan, siklus perpindahan panas yang terjadi pada fluida kerja yang ada di dalam evaporator semakin cepat dalam menyerap dan membuang panas. Sehingga berpengaruh pada waktu 
yang diperlukan untuk mencapai keadaan stable.

Pada Gambar 3 juga ditunjukkan fenomena overshoot, zigzag, dan steady. Untuk fenomena overshoot yang terjadi adalah pada bagian evaporator mengalami kenaikan suhu yang disebabkan oleh beban kalor yang diberikan ke evaporator secara terus-menerus sehingga fluida kerja cair yang berada di dalam tersebut mengalami proses evaporasi menjadi uap air. Uap air tersebut mengalir melewati bagian adiabatic diikuti kenaikkan suhu pada daerah tersebut. Pada keadaan ini, belum terjadi sirkulasi secara baik sehingga suhu evaporator mengalami peningkatan yang cukup signifikan.

Dari Gambar 3 dapat dilihat setelah fenomena overshoot selesai kemudian diikuti dengan fenomena zigzag. Pada keadaan ini, sirkulasi mulai berjalan namun belum pada keadaan yang stabil. Ketidakstabilan ini terlihat dari pola distribusi suhu pada bagian evaporator dan condenser yang cukup berfluktuatif.

Fenomena berikutnya yang dapat dilihat pada Gambar 3 adalah fenomena stable. Keadaan ini menunjukkan bahwa distribusi suhu pada LHP mencapai kestabilan secara keseluruhan karena sirkulasi alam di dalam LHP telah berjalan dengan baik. Fenomena ini berarti pada keadaan stable, penyerapan kalor dan pembuangan kalor oleh LHP telah berjalan dengan baik.

\section{Perbandingan Suhu Adiabatic}

Pada Gambar 4 dapat dilihat performa dari bagian pipa kapiler adiabatic dengan diberikan beban kalor sebesar $35^{\circ} \mathrm{C}, 45^{\circ} \mathrm{C}$, $55^{\circ} \mathrm{C}$, dan $65^{\circ} \mathrm{C}$, serta menggunakan filling ratio $200 \%$. Laju aliran udara pendingin 2 $\mathrm{m} / \mathrm{s}$.

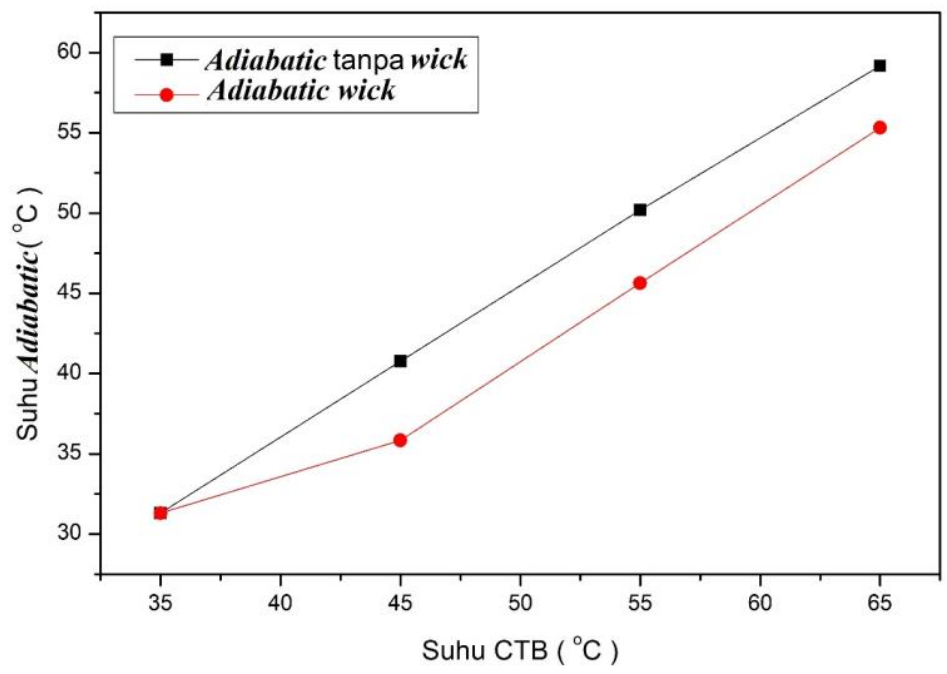

Gambar 4. Perbedaan suhu adiabatic tanpa wick dan dengan wick

Dari Gambar 4 dapat dilihat suhu pada bagian adiabatic dengan wick lebih rendah dibanding pada bagian adiabatic tanpa wick. Fenomena ini menunjukkan bahwa uap yang sudah terevaporasi di bagian evaporator agar mengalir terlebih dahulu menuju pipa kapiler adiabatic tanpa wick. Hal ini dapat dilihat dari suhu kedua pipa adiabatic yang berbeda. Pada suhu $35^{\circ} \mathrm{C}$ dapat dilihat kedua suhu adiabatic tanpa wick dan adiabatic wick memiliki suhu berkisar $31^{\circ} \mathrm{C}$.

Hal ini menunjukkan pada suhu $35^{\circ} \mathrm{C}$ LHP belum bisa bekerja secara optimal karena evaporator meyerap suhu dari CTB 
masih rendah. Selanjutnya pada suhu CTB $45^{\circ} \mathrm{C}$, bagian adiabatic tanpa wick berada pada suhu $40^{\circ} \mathrm{C}$ berbeda dengan adiabatic dengan wick yang memiliki suhu lebih rendah yaitu $35^{\circ} \mathrm{C}$. Lalu pada suhu CTB di $55^{\circ} \mathrm{C}$, bagian adiabatic tanpa wick memiliki suhu sebesar $50^{\circ} \mathrm{C}$ dan adiabatic dengan wick memiliki suhu lebih rendah yaitu $45^{\circ} \mathrm{C}$.

Kemudian di suhu CTB $65^{\circ} \mathrm{C}$ terlihat suhu bagian adiabatic tanpa wick lebih tinggi yaitu sebesar $59^{\circ} \mathrm{C}$ dibandingkan adiabatic wick yang lebih rendah yaitu sebesar $55^{\circ} \mathrm{C}$. Hal ini menunjukkan bagian adiabatic dengan wick dapat menahan uap pada saat terjadi evaporasi di bagian evaporator.

\section{Hambatan Termal}

Pada Gambar 5 ditunjukkan hambatan termal model LHP dengan memberikan beban kalor sebesar $35^{\circ} \mathrm{C}, 45^{\circ} \mathrm{C}, 55^{\circ} \mathrm{C}$, dan $65^{\circ} \mathrm{C}$ dengan menggunakan filling ratio sebesar $200 \%$ dan kecepatan udara pendingin sebesar $2 \mathrm{~m} / \mathrm{s}$.

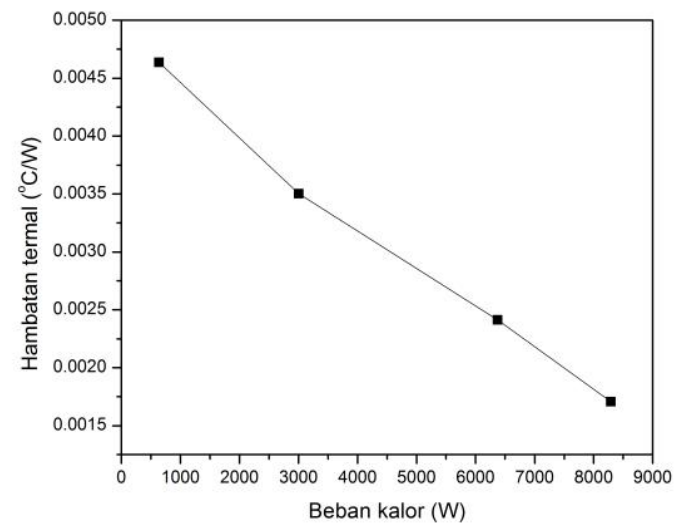

Gambar 5. Hambatan termal LHP pada filling ratio $200 \%$ dan laju aliran udara $2 \mathrm{~m} / \mathrm{s}$.
Dari Gambar 5 terlihat hambatan termal terkecil pada LHP sebesar $0,0017{ }^{\circ} \mathrm{C} / \mathrm{W}$, yaitu ketika LHP dioperasikan dengan beban kalor $65^{\circ} \mathrm{C}$. Hambatan termal menjadi kecil karena semakin besar beban kalor yang diberikan ke evaporator akan meningkatkan jumlah uap hasil pendidihan yang naik ke condenser dan mempercepat siklus perpindahan kalor pada LHP secara menyeluruh untuk mencapai keadaan stable-nya.

\section{KESIMPULAN}

Kesimpulan dari hasil studi yang diperoleh menunjukkan bahwa wick dapat berfungsi dengan baik untuk menahan uap tidak naik ke bagian condenser dan sebagai jalur fluida hasil kondensasi untuk kembali ke evaporator pada kondisi suhu diatas $35^{\circ} \mathrm{C}$ ketika evaporator menyerap suhu yang semakin meningkat. Fenomena perpindahan kalor yang didapatkan menunjukkan bahwa LHP dengan wick ini memiliki kesamaan fenomena distribusi suhu seperti heat pipe pada umumnya, yaitu overshoot, zigzag, dan stable. Model LHP ini memiliki hambatan termal yang sangat kecil sebesar $0,0017^{\circ} \mathrm{C} / \mathrm{W}$ diperoleh saat model LHP dioperasikan pada beban kalor $65^{\circ} \mathrm{C}$.

Hasil ini menunjukkan semakin tinggi beban kalor yang diberikan di evaporator menyebabkan semakin kecilnya nilai hambatan termal, sehingga kemampuan LHP dalam menyerap dan membuang kalor menjadi sangat baik. Diharapkan studi ini 
dapat digunakan sebagai salah satu dasar untuk mendesain prototipe LHP.

\section{UCAPAN TERIMAKASIH}

Terima kasih kepada Badan Tenaga Nuklir National khususnya pada Pusat Teknologi dan Keselamatan Reaktor Nuklir serta pembimbing praktisi atas ilmu pengetahuan yang telah diberikan dan kesempatan untuk melakukan penelitian tugas akhir.

\section{DAFTAR PUSTAKA}

[1] W. N. S. Nandy Putra, "Teknologi Pipa Kalor,” p. 185, 2014.

[2] M. H. Kusuma, "Studi Eksperimental Model Loop Heat Pipe sebagai System Pendingin Pasif di Kolam Pengambil Panas Small Modular Reactor," 2019.

[3] M. H. Kusuma et al., "Passive cooling system in a nuclear spent fuel pool using a vertical straight wickless-heat pipe," Int. J. Therm. Sci., vol. 126, pp. 162-171, 2018, doi: 10.1016/j.ijthermalsci.2017.12.033.

[4] M. Hadi Kusuma, "Sistem Pendingin Pasif di Kolam Penyimpanan Bahan Bakar Bekas Nuklir dengan Menggunakan Pipa Kalor," Universitas Indonesia, 2017.

[5] K. Zhu, X. Li, H. Li, Z. Yang, and Y. Wang, "Experimental investigation on the effect of heat sink temperature on operational characteristics of a newtype loop heat pipe," Energy Procedia, vol. 158, pp. 2423-2429, 2019 , doi: 10.1016/j.egypro.2019.01.298.

[6] C. Wang et al., "Experimental study on heat transfer limit of high temperature potassium heat pipe for advanced reactors," Ann. Nucl.
Energy, vol. 151, p. 107935, 2021, doi: 10.1016/j.anucene.2020.107935.

[7] N. Putra, Yanuar, and F. N. Iskandar, "Application of nanofluids to a heat pipe liquid-block and the thermoelectric cooling of electronic equipment," Exp. Therm. Fluid Sci., vol. 35, no. 7, pp. 1274-1281, 2011, doi:

10.1016/j.expthermflusci.2011.04.015

[8] N. Putra, W. N. Septiadi, R. Sahmura, and C. T. Anggara, "Application of $\mathrm{Al} 2 \mathrm{O} 3$ nanofluid on sintered copperpowder vapor chamber for electronic cooling," Adv. Mater. Res., vol. 789, pp. 423-428, 2013, doi: 10.4028/www.scientific.net/AMR.789 .423 .

[9] S. W. Chi, "Heat pipe theory and practice," hemi, 1976.

[10] A. Faghri, Heat pipe science and technology. Global Digital Press, 1995.

[11] L. L. Vasiliev, "Heat pipes in modern heat exchangers," Appl. Therm. Eng., vol. 25 , no. 1 , pp. 1-19, 2005, doi: 10.1016/j.applthermaleng. 2003.12.00 4.

[12] H. Akachi, "Structure of a heat pipe." Google Patents, May 1990.

[13] K. S. Udell, "Heat transfer in porous media considering phase change and capillarity - the heat pipe effect," Int. J. Heat Mass Transf., vol. 28, no. 2, pp. 485-495, 1985.

[14] T. Brahim and A. Jemni, "CFD analysis of hotspots copper metal foam flat heat pipe for electronic cooling applications," Int. J. Therm. Sci., vol. 159, no. December 2019, p. 106583, 2021, doi: 10.1016/j.ijthermalsci.2020.106583.

[15] K. Grissa, A. M. Benselama, Z. Lataoui, Y. Bertin, and A. Jemni, "Investigations of the thermal performance of a cylindrical wicked heat pipe," Int. J. Energy Res., vol. 42, no. 9, pp. 3048-3058, 2018, doi: 10.1002/er.3973.

[16] D. Somasundaram, A. Mani, and M. 
Kamaraj, "Experimental investigation of thermal performance of metal foam wicked flat heat pipe," Exp. Therm. Fluid Sci., vol. 82, pp. 482-492, 2017 , doi: 10.1016/j.expthermflusci.2016.12.006

[17] K. Odagiri and H. Nagano, "Heat transfer characteristics of flat evaporator loop heat pipe under high heat flux condition with different orientations," Appl. Therm. Eng., vol. 153, no. February, pp. 828-836, 2019, doi:

10.1016/j.applthermaleng.2019.02.02 2.

[18] I. Setyawan, S. R. Riawan, S. P. Sari, and Ridwan, "Analisis Kinerja Pipa Kalor Lurus Menggunakan Sumbu Kapiler Screen Mesh 300 Dengan Memvariasikan Filling Rasio," $J$. ASIIMETRIK J. Ilm. Rekayasa Inov., vol. 2, no. 2, pp. 133-138, 2020, doi: 10.35814/asiimetrik.v2i2.1470.

[19] C. Liu, R. Xie, N. Li, D. Lu, F. Hong, and $\mathrm{Y} . \mathrm{Wu}$, "Experimental study of loop heat pipes with different working fluids in 190-260 K," Appl. Therm. Eng., vol. 178, no. September 2019, p. 115530, 2020, doi: 10.1016/j.applthermaleng.2020.11553 0 . 